\title{
REVIEW
}

\section{Ageing and the brain}

\author{
R Peters
}

Postgrad Med J 2006;82:84-88. doi: 10.1136/pgmj.2005.036665

Ageing causes changes to the brain size, vasculature, and cognition. The brain shrinks with increasing age and there are changes at all levels from molecules to morphology. Incidence of stroke, white matter lesions, and dementia also rise with age, as does level of memory impairment and there are changes in levels of neurotransmitters and hormones. Protective factors that reduce cardiovascular risk, namely regular exercise, a healthy diet, and low to moderate alcohol intake, seem to aid the ageing brain as does increased cognitive effort in the form of education or occupational attainment. A healthy life both physically and mentally may be the best defence against the changes of an ageing brain. Additional measures to prevent cardiovascular disease may also be important.

Correspondence to: Ruth Peters, Care of the Elderly, Imperial College Faculty of Medicine, Hammersmith campus, Du Cane Road, London W12 ONN, UK; r.peters@ imperial.ac.uk

Submitted 28 April 2005 Accepted 20 May 2005
$\mathrm{T}$ he effects of ageing on the brain and cognition are widespread and have multiple aetiologies. Ageing has its effects on the molecules, cells, vasculature, gross morphology, and cognition. As we age our brains shrink in volume, particularly in the frontal cortex. As our vasculature ages and our blood pressure rises the possibility of stroke and ischaemia increases and our white matter develops lesions. Memory decline also occurs with ageing and brain activation becomes more bilateral for memory tasks. This may be an attempt to compensate and recruit additional networks or because specific areas are no longer easily accessed. Genetics, neurotransmitters, hormones, and experience all have a part to play in brain ageing. But, it is not all negative, higher levels of education or occupational attainment may act as a protective factor. Also protective are a healthy diet, low to moderate alcohol intake, and regular exercise. Biological ageing is not tied absolutely to chronological ageing and it may be possible to slow biological ageing and even reduce the possibility of suffering from age related diseases such as dementia.

\section{PHYSICAL CHANGES}

It has been widely found that the volume of the brain and/or its weight declines with age at a rate of around $5 \%$ per decade after age $40^{1}$ with the actual rate of decline possibly increasing with age particularly over age $70 .^{2}$ The manner in which this occurs is less clear. The shrinking of the grey matter is frequently reported to stem from neuronal cell death ${ }^{3-5}$ but whether this is solely responsible or even the primary finding is not entirely clear. ${ }^{6}$ It has been suggested that a decline in neuronal volume rather than number contributes to the changes in an ageing brain and that it may be related to sex with different areas most affected in men and women. ${ }^{7}$ Additionly, there may be changes in dentritic arbour, spines, and synapses. Dendritic sprouting may occur thus maintaining a similar number of synapses $^{5}$ and compensating for any cell death. ${ }^{4}$ Conversely a decrease in dendritic synapses or loss of synaptic plasticity has also been described. ${ }^{8}$ Functional organisational change may occur and compensate in a similar way to that found in patients after recovery from moderate traumatic brain injury. ${ }^{9}$ However research in the latter area suffers from small numbers of cases. The role of white matter in the ageing brain also needs to be considered. ${ }^{3}$ White matter may decline with age, the myelin sheath deteriorating after around the age of 40 even in normal ageing and it has been suggested that the late myelinating regions of the frontal lobes are most affected by white matter lesions (WML) ${ }^{10-}$ ${ }^{12}$ ) although not all studies support this view. ${ }^{13}$ Leukoariosis/WML increase with age and may indicate subclinical ischaemia. They will be discussed in more detail below.

Brain changes do not occur to the same extent in all brain regions. ${ }^{6}$ That these brain changes are not uniform is supported by a longitudinal study, using two MRI scans separated by around one or two years, ${ }^{2}$ and by a review of cross sectional studies. The latter included only those studies that compared younger (aged less than 30) and older (greater than 60) groups to compare wider age ranges and in contrast with much of the other work in this area. The review looked at volume and found that the prefrontal cortex was the most affected. The striatum came second with the analysis including over seven studies. The temporal lobe, cerebellar vermis, cerebellar hemispheres, and hippocampus also reduced volume with between 8 and 18 studies and the prefrontal white matter also showed a reduction (five studies). The occipital cortex was the least affected (five studies). ${ }^{3}$ The finding that the prefrontal cortex is most affected and the occipital least, fits well with the cognitive changes seen in ageing, although some studies also suggest that ageing has the greatest effect in the hippocampus. ${ }^{48}$ Men and women may also differ with frontal and temporal lobes most affected in men compared with the hippocampus and parietal lobes in women. ${ }^{7}{ }^{14}$ Finally the rate of reduction in brain volume may increase with

Abbreviations: AD, Alzheimer's disease; WML, white matter lesion; $\mathrm{VaD}$, vascular dementia

This article is part of a series on ageing edited by Professor Chris Bulpitt. 
age particularly over 70 although numbers studied are very small. ${ }^{2}$ Because of the individual differences seen in brain development and ageing ${ }^{15}$ mapping structure to function and change because of ageing is a complex task, ${ }^{16}$ however there are studies that show links between volume and neuropsychological function. A study looking at cortical volume and white matter hyperintensity volume in 140 people aged 50 to 81 years pre-screened for dementia and depression, found an association between increasing age, a reduction in prefrontal cortical volume, increased subcortical white matter lesions, and an increase in perseverative behaviour (decreased executive function). ${ }^{17}$

\section{COGNITIVE CHANGE}

The most widely seen cognitive change associated with ageing is that of memory. Memory function can be broadly divided into four sections, episodic memory, semantic memory, procedural memory, and working memory. ${ }^{18}$ The first two of these are most important with regard to ageing. Episodic memory is defined as "a form of memory in which information is stored with 'mental tags', about where, when and how the information was picked up". ${ }^{19}$ An example of an episodic memory would be a memory of your first day at school, the important meeting you attended last week, or the lesson where you learnt that Paris is the capital of France. Episodic memory performance is thought to decline from middle age onwards. This is particularly true for recall in normal ageing and less so for recognition. ${ }^{20}$ It is also a characteristic of the memory loss seen in Alzheimer's disease (AD). ${ }^{18}$

Semantic memory is defined as "memory for meanings", for example, knowing that Paris is the capital of France, that 10 millimetres make up a centimetre, or that Mozart composed the Magic Flute. ${ }^{19}$ Semantic memory increases gradually from middle age to the young elderly but then declines in the very elderly. ${ }^{20}$ It is not yet clear why these changes occur and it has been hypothesised that the very elderly have less resources to draw on and that their performance may be affected in some tasks by slower reaction times, lower attentional levels, slower processing speeds, detriments in sensory and or perceptual functions, or potentially a lesser ability to use strategies..$^{20-23}$

There have been studies investigating different types of memory in ageing using neuropsychological testing and neuroimaging. However, it must be pointed out that it is sometimes methodologically difficult to separate some of these functions, for example episodic memory encoding and semantic memory retrieval. ${ }^{24}$ Despite this studies are beginning to examine performance on memory tasks with ageing and by neuroimaging. A review article focusing in this area highlighted the changes in regional brain activation. ${ }^{24}$ Older brains tend to show more symmetrical activation, either because they have increased activation in a hemisphere that is less activated than in younger adults or because they show reduced activation in the areas most activated in younger adults. This has been shown for visual perception and in memory tasks. ${ }^{24}$ The observed changes in activation in the left and right prefrontal cortex are in keeping with changes in memory performance, particularly episodic memory, as this is thought to be based in this area. ${ }^{24}$ It has also been suggested that the actual level of brain activation, as shown in neuroimaging, may be related more directly to the levels of memory performance. ${ }^{25}$ A review of studies using electroencephalograms to examine event related potentials in response to stimuli also contribute some support for increased symmetry in brain activation with age. ${ }^{26}$

The increased symmetrical hemispheric activation is a robust finding and has been referred to as HAROLD or hemispheric asymmetry reduction in older adults. It is not clear whether this change is an attenuation of the response seen in younger subjects, an inability to recruit specific areas, or an attempt to compensate for the ageing process. ${ }^{21} 23$ This change in activation occurring in the frontal lobes fits with changes in memory performance and with the possible white matter changes referred to above, however, other factors such as changes in neurotransmitter or hormone levels also require consideration.

\section{MECHANISMS OF CHANGE}

The neurotransmitters most often discussed with regard to ageing are dopamine and serotonin. Dopamine levels decline by around $10 \%$ per decade from early adulthood and have been associated with declines in cognitive and motor performance. ${ }^{2027}$ It may be that the dopaminergic pathways between the frontal cortex and the striatum decline with increasing age, or that levels of dopamine itself decline, synapses/receptors are reduced or binding to receptors is reduced ${ }^{20}$ Serotonin and brain derived neurotrophic factor levels also fall with increasing age and may be implicated in the regulation of synaptic plasticity and neurogenesis in the adult brain ${ }^{28}$ A substance related to neurotransmitter levels, monoamine oxidase, increases with age and may liberate free radicals from reactions that exceed the inherent antioxidant reserves. ${ }^{29}$ Other factors that have been implicated in the ageing brain include calcium dysregulation, ${ }^{30}$ mitochondrial dysfunction, and the production of reactive oxygen species. ${ }^{31}$

Another factor to consider with regard to the ageing brain and its cognitive performance is hormonal influence. It is known that sex hormones can affect cognitive processes in adulthood and that changes in sex hormones occur in ageing particularly in women at menopause. Women also have a higher incidence of $\mathrm{AD}$ even when longer life expectancy is taken into account. ${ }^{14} \mathrm{AD}$ is characterised by failing memory and there has been a suggestion that oestrogen therapy may increase dopaminergic responsivity ${ }^{32}$ and play a protective part in $\mathrm{AD} .{ }^{33}{ }^{34}$ It must be remembered though that the use of HRT has recently been shown to have cancer risks. ${ }^{35}$ Growth hormone levels also decline with age and may be associated with cognitive performance although the evidence is far from clear. $^{36}$

The ageing brain may also suffer from impaired glucose metabolism ${ }^{20}$ or a reduced input of glucose or oxygen as cerebrovascular efficiency falls, although reduction in glucose may partly be attributable to atrophy rather than any change in glucose metabolism. ${ }^{37}$ Change in vasculature is important and another common finding in elderly brains related to ischaemia are white matter lesions and stroke.

\section{VASCULAR FACTORS AND DEMENTIA}

WML, strokes, and dementia increase with increasing age. $^{10} 123839$ WML show levels of heritability, ${ }^{40}$ are common in the elderly even when asymptomatic and are not the benign finding they were once thought to be. ${ }^{11}{ }^{41}$ For a review see Hsu-Ko. ${ }^{42}$ WML or hyperintensities are related to increased cardiovascular risk ${ }^{13} 42$ and a reduction in cerebral blood flow, cerebral reactivity, ${ }^{43}$ and vascular density although it is unclear if the WML prompt the vessel loss or vice versa. ${ }^{44}$ They may also associated with further tissue changes in grey matter visible when using magnetisation transfer magnetic resonance imaging. ${ }^{45}$ WML are found more in frontal rather than posterior brain regions in keeping with cognitive and morphological findings discussed above ${ }^{10}{ }^{12}$ ) and the fact that WML are related to poor cognition has been shown. ${ }^{13} 46$ Other damage associated with ageing and related to blood pressure and vascular factors include strokes and small vessel disease. Moderate to high 24 hour ambulatory blood pressure has been related to increased brain atrophy as has increased variability of systolic blood 
pressure. ${ }^{47}$ In Japanese subjects raised systolic blood pressure was related to grey matter volume loss in a cross sectional study ${ }^{48}$ and in the Framingham offspring cohort an increased 10 year risk of first stroke was associated with decrements in cognitive function. ${ }^{38}$ The authors suggest that this may be attributable to cerebrovascular related injuries, accelerated atrophy, white matter abnormalities, or asymptomatic infarcts. ${ }^{38}$ That cerebral vasculature could be related to cognitive function is not surprising because microvasculature ability to respond to metabolic demand falls with increasing age and moreover functional adult neurogenesis ${ }^{49}{ }^{50}$ may be related to good capilliary growth. For reviews see Lie et al and Riddle et al..$^{51}{ }^{52}$ In addition to this there have been many links made between dementia, even $\mathrm{AD}$, and vascular risk factors. ${ }^{53-55}$

Increasing evidence points to vascular factors not only contributing to cognitive problems in ageing but also to the two most common dementias seen in this population. The prevalence of dementia increases almost exponentially with increasing age with around $20 \%$ of those aged 80 affected rising to $40 \%$ of those aged $90 .{ }^{39}$

The dementia types seen most frequently in the elderly are $\mathrm{AD}$ accounting for around $40 \%-70 \%$ of dementias, and vascular dementia (VaD) $15 \%-30 \% .^{39}{ }^{56}$ In recent years, it has seemed increasingly likely that there is an overlap between these two dementias ${ }^{57}$ and there have been calls for $\mathrm{AD}$ to be reclassified as a vascular disorder ${ }^{58}$ or for dementia to become a multifactorial disorder ${ }^{59}$ A postmortem study found that $77 \%$ of $\mathrm{VaD}$ cases showed $\mathrm{AD}$ pathology ${ }^{60}$ and high blood pressure has been associated with increased neurofibrilliary tangles characteristic of $\mathrm{AD} .^{61}$ Multiple types of vascular pathology have been associated with AD including microvascular degeneration, disorders of the blood-brain barrier, WML, microinfarctions, and cerebral haemorrhages. ${ }^{62}$ It has been suggested that large vessel factors, for example, atherosclerosis, increase the risk of $\mathrm{AD}^{63}$ and may play a part in cerebral vessel amyloid deposition. ${ }^{64} \mathrm{AD}$ patients do show significantly higher levels of cerebrovascular pathology when compared with controls at postmortem examination ${ }^{65}$ although this did not correlate with severity of cognitive decline. A similar finding, that small infarcts in $\mathrm{AD}$ do not affect the rate of cognitive decline, ${ }^{66}$ suggests that vascular factors may unmask or magnify underlying AD pathology, ${ }^{62}{ }^{67}$ or shorten the pre-clinical phase of $\mathrm{AD}$, at least in Western populations. ${ }^{68}$ Alternatively multiple risk factors may be acting together. ${ }^{69} 70$ The characteristic neurofibrilliary tangles and plaques found in $\mathrm{AD}$ are also evident to some degree in most elderly brains at postmortem examination even those without symptoms, as are white matter lesions. ${ }^{71}$

The issue of normal ageing is a difficult one because there are studies that show cognitively intact adults aged 100,72 73 and yet a high percentage suffer from dementia and the line between mild cognitive impairment and normal memory changes $^{74}$ is still a little blurred. ${ }^{75}{ }^{76}$ What is in no doubt is that changes in brain vasculature, WML and intra/extra cellular changes are likely to begin in midlife. ${ }^{71}$ There are many influences on the ageing brain, genetics, biological, and environmental influences all of which contribute to the physiological and cognitive changes ${ }^{77}{ }^{78}$; Mattson ${ }^{79}$ provided a review.

Risk factors that have been put forward with regard to ageing and development of dementia include hypertension, diabetes, hyperhomocysteinaemia, and a high cholesterol although the evidence for all but hypertension is far from clear. ${ }^{80-87}$ Protective factors include diet, alcohol, exercise, and intellectual pursuits.

\section{PROTECTIVE FACTORS}

That diet may have a part to play in biological ageing and the development of cognitive decline is raised by studies showing that a diet higher in energy and lower in antioxidants is a risk factor $^{88}$ alongside studies showing that energy restriction may prolong life, ${ }^{79} 89$ reduce oxidative damage, ${ }^{90}$ or ameliorate/ protect against cognitive decline. ${ }^{79} 8991$ Increased consumption of fish and seafood, even only once a month, may be protective and reduce stroke. ${ }^{92}$ Consumption of antioxidant supplements ${ }^{93}$ may be protective although the evidence for other preparations purported to aid cognitive function, such as ginkgo biloba or piracetam is mixed. ${ }^{94}$ In addition to a healthy diet, low to moderate alcohol intake may reduce cardiovascular risk and may stimulate the hippocampus. Alcohol seems to show a U or J shaped curve such that teetotal people or heavy drinkers are disadvantaged whereas moderate drinkers show reduced WML, infarcts, and even dementia. ${ }^{95-98}$ Exercise is also beneficial and studies have shown increasing executive functioning and even reduction in the ageing expected decline of white and grey tissue density with increased fitness. ${ }^{99}{ }^{100}$ As is shown by the studies mentioned above, biological age is not always synchronised with chronological age particularly with regard to cardiovascular risk factors. ${ }^{101}$ Lower cardiovascular risk may be linked to lower biological age and vice versa. Another factor to consider with regard to cognitive decline is the effect of intelligence and environmental factors such as schooling and occupation contributing to a cognitive reserve that protects against decline despite neuropathology ${ }^{22}{ }^{102-104}$ although there is not total support for this theory. ${ }^{105}$

\section{CONCLUSION}

That the brain changes with increasing chronological age is clear, however, less clear is the rate of change, the biological age of the brain, and the processes involved. The brain changes that may affect cognition and behaviour occur at the levels of molecular ageing, intercellular and intracellular ageing, tissue ageing, and organ change. There are many areas of research under investigation to elucidate the mechanisms of ageing and to try to alleviate age associated disorders, particularly dementias that have the biggest impact on the population. In terms of personal brain ageing the studies suggest that a healthy lifestyle that reduces cardiovascular risk will also benefit the brain. Medical care in this area may even offer limited protection in terms of cognitive decline but this needs to be shown for antihypertensives, antiplatelet, and anticholesterol agents. It is also important to take note of the limitations in studies on the ageing brain. Many studies are cross sectional in nature, have small numbers of participants with wide ranges in chronological age, lack control for risk factors or protective factors, take no account of education that may improve performance on cognitive tests, and finally lack assessment with regard to depression that may also affect performance. It must be remembered that the brains of an elderly group may show cohort effects related to wider environmental influences, for example, lack of high energy foods while growing up. ${ }^{2}$ It is also extremely difficult to separate out and measure single cognitive processes to fully understand any changes. ${ }^{106}$

Future studies need to take full account of these factors and "cross sequential", a combination of cross sectional and longitudinal studies, have been proposed. ${ }^{3}$ It is clear that our understanding of the ageing brain continues to grow but still requires much research that is especially important given the numbers of elderly people in society and their potential levels of cognitive impairment. Where appropriate, randomised controlled trials of therapeutic measures may, in future, lead the way to greater understanding.

Funding: none.

Conflicts of interest: none. 


\section{REFERENCES}

1 Svennerholm L, Boström K, Jungbjer B. Changes in weight and compositions of major membrane components of human brain during the span of adult human life of Swedes. Acta Neuropathol 1997;94:345-52.

2 Scahill R, Frost $C$, Jenkins $R$, et al. A longitudinal study of brain volume changes in normal ageing using serial registered magnetic resonance imaging. Arch Neurol 2003;60:989-94.

3 Raz N. The ageing brain: structural changes and their implications for cognitive ageing. In: Dixon R, Bäckman L, Nilsson L, eds. New frontiers in cognitive ageing. Oxford: Oxford University Press, 2004:115-34.

4 Anderton B. Ageing of the brain. Mech Ageing Dev 2002;123:811-17.

5 Kolb B, Wishaw I. Brain plasticity and behaviour. Annu Rev Psychol 1998:49:43-64

6 Trollor J, Valenzuela M. Brain ageing in the new millennium. Austr N Z J Psychiatry 2001;35:788-805.

7 Murphy D, DeCarli C, Mclntosh A, et al. Sex differences in human brain morphometry and metabolism: an in vivo quantitative magnetic resonance imaging and positron emission tomography study on the effect of ageing. Arch Gen Psychiatry 1996;53:585-94.

8 Barnes C. Long-term potentiation and the ageing. Philos Trans Royal Soc Lond B Biol Sci 2003;358:765-72.

9 Levine B, Cabeza R, McIntosh A, et al. Functional reorganisation of memory after traumatic brain injury: a study with $\mathrm{H}_{2}{ }^{15} \mathrm{O}$ positron emission tomography. J Neurol Neurosurg Psychiatry 2002;73:173-81.

10 Bartzokis G, Cummings J, Sultzer D, et al. White matter structural integrity in healthy ageing adults and patients with Alzheimer disease. Arch Neurol 2003;60:393-8

11 Tullberg M, Fletcher E, DeCarli C, et al. White matter lesions impair frontal lobe function regardless of their location. Neurology 2004;63:246-53.

12 Head D, Buckner R, Shimony J, et al. Differential vulnerability of anterior white matter in nondemented ageing with minimal acceleration in dementia of the Alzheimer type: evidence from diffusion tensor imaging. Cereb Cortex 2004; 14:410-23.

13 Artero $\mathrm{S}$, Tiemeier $\mathrm{H}$, Prins $\mathrm{N}$, et al. Neuroanatomical localisation and clinical correlates of white matter lesions in the elderly. I Neurol Neurosurg Psychiatry 2004;75:1304-8.

14 Compton J, Van Amelsoort T, Murphy D. HRT and its effect on normal ageing of the brain and dementia. Br J Clin Pharmacol 2001;52:647-53.

15 Hultsch D, Macdonald S. Intraindividual variability in performance as a theoretical window onto cognitive ageing. In: Dixon R, Bäckman L, Nilsson L, eds. New frontiers in cognitive ageing. Oxford: Oxford University Press, 2004:65-88.

16 Gallagher M, Rapp P. The use of animal models to study the effects of ageing on cognition. Annu Rev Psychol 1997;48:339-70.

17 Gunning-Dixon F, Raz N. Neuroanatomical correlates of selected executive functions in middle aged and older adults: a prospective MRI study. Neuropsychologia 2003;41:1929-41.

18 Parkin A. Memory and amnesia. Oxford: Blackwall, 1997.

19 Reber AS. Dictionary of psychology. London: Penguin, 1995

20 Nyberg L, Bäckman L. Cognitive ageing: a view from brain imaging. In: Dixon R, Bäckman L, Nilsson L, eds. New frontiers in cognitive ageing. Oxford: Oxford University Press, 2004:135-60.

21 Cabeza R. Commentary: neuroscience frontiers of cognitive ageing: approaches to cognitive neuroscience of ageing. In: Dixon R, Bäckman L, Nilsson L, eds. New frontiers in cognitive ageing. Oxford: Oxford University Press, 2004:179-98.

22 Lustig C, Buckner R. Preserved neural correlates of priming in old age and dementia. Neuron 2004:42:865-75.

23 Cabeza R, Daselaar S, Dolcos F, et al. Task-independent and task-specific age effects on brain activity during working memory, visual attention and episodic retrieval. Cerebral Cortex 2004; 14:364-75.

24 Cabeza R. Cognitive neuroscience of ageing: contributions of functional neuroimaging. Scand J Psychol 2001;42:277-86.

25 Rosen A, Prull M, O'Hara R, et al. Variable effects of ageing on frontal lobe contributions to memory. Neuroreport 2002;13:2425-8.

26 Friedman D. Cognition and ageing: a highly selective overview of eventrelated potential (ERP) data. J Clin Exp Neuropsychol 2003;25:702-20.

27 Mukherjee J, Christian B, Dunigan K, et al. Brain imageing of ${ }^{18} \mathrm{~F}$-Fallypride in normal volunteers: blood analysis, distribution, test-retest studies, and preliminary assessment of sensitivity to ageing effects on dopamine D-2/D-3 receptors. Synapse 2002;46:170-88.

28 Mattson M, Maudsley S, Martin B. BDNF and 5-HT: a dynamic duo in agerelated neuronal plasticity and neurodegenerative disorders. Trends Neurosci 2004;27:589-94.

29 Volchegorskii I, Shemyakov S, Turygin $\mathrm{V}$, et al. The age dynamics of monoamine oxidase activity and levels of lipid peroxidation products in the human brain. Neurosci Behav Physiol 2004;34:303-5.

30 Toescu E, Verkhratsky A, Landfield P. $\mathrm{Ca}^{2+}$ regulation and gene expression in normal brain ageing. Trends Neurosci 2004;27:614-20.

31 Melov S. Modeling mitochondrial function in ageing neurons. Trends Neurosci 2004;27:601-6.

32 Craig $M$, Cutter W, Wickham $H$, et al. Effect of long term estrogen therapy on dopaminergic responsivity in post menopausal women-a preliminary study. Psychoneuroendocrinology 2004;29:1309-16.

33 Herlitz A, Yonker J. Hormonal effects on cognition in adults. In: Dixon R, Bäckman L, Nilsson L, eds. New frontiers in cognitive ageing. Oxford: Oxford University Press, 2004:253-78.

34 Tan Z, Seshadri S, Beiser A, et al. Bone mineral density and the risk of Alzheimer disease. Arch Neurol 2005;62:107-11.
$35 \mathrm{Ng} \mathrm{C}$, Panay N. Hormone replacement therapy update. Geriatric Medicine 2004;34:27-34.

36 Sytze van Dam P, Aleman A. Insulin - like growth factor-I, cognition and brain ageing. Eur J Pharmacol 2004:490:87-95.

37 Ibáñez V, Pietrini P, Furey $M$, et al. Resting state brain glucose metabolism is not reduced in normotensive healthy men during ageing, after correction for brain atrophy. Brain Res Bull 2004;63:147-54.

38 Elias M, Sullivan L, Agostino R, et al. Framingham stroke risk profile and lowered cognitive performance. Stroke 2004;35:404-9.

39 Lobo A, Launer L, Fratiglioni L, for the Neurologic Diseases in the Elderly Research Group, et al. Prevalence of dementia and major subtypes in Europe: a collaborative study of population based-cohorts. Neurology 2000:54:S4-5

40 Atwood L, Wolf P, Heard-Costa N, et al. Genetic variation in white matter hyperintensity volume in the Framingham study. Stroke 2004;35:1609-13.

41 Petkov C, Wu C, Eberling J, et al. Correlates of memory function in community-dwelling elderly: the importance of white matter hyperintensities. J Int Neuropsychol Soc 2004;10:371-81.

42 Kuo H, Lipsitz L. Cerebral white matter changes and geriatric syndromes: is there a link? J Gerontol 2004;59A:818-26.

43 Marstrand J, Garde E, Rostrup E, et al. Cerebral perfusion and cerebrovascular reactivity are reduced in white matter hyperintensities. Stroke 2002;33:972-6.

44 Moody D, Thore C, Anstrom J, et al. Quantification of afferent vessels shows reduced brain vascular density in subjects with leukoaraiosis. Radiology 2004;233:883-90.

45 Mezzapesa D, Rocca M, Pagini E, et al. Evidence of subtle gray-matter pathologic changes in healthy individuals with nonspecific white-matter hyperintensities. Arch Neurol 2003;60:1 109-12.

46 Kövari E, Gold G, Herrmann F, et al. Cortical microinfarcts and demyelination significantly affect cognition in brain ageing. Stroke 2004;35:410-14.

47 Goldstein I, Bartzokis G, Guthrie D, et al. Ambulatory blood pressure and brain atrophy in the healthy elderly. Neurology 2002;59:713-19.

48 Taki Y, Goto R, Evans A, et al. Voxel-based morphometry of human brain with age and cerebrovascular risk factors. Neurobiol Ageing 2004;25:455-63

49 Finch C. Neurons, glia, and plasticity in normal brain ageing. Neurobiol Ageing 2003;24:S123-7.

50 Kempermann G, Wiskott L, Gage F. Functional significance of adult neurogenesis. Curr Opin Neurobiol 2004;14:186-91.

51 Lie D, Song H, Colamarino S, et al. Neurogenesis in the adult brain: new strategies for central nervous system diseases. Annu Rev Pharmacol Toxicol 2004:44:399-421.

52 Riddle D, Sonntag W, Lichtenwalner R. Microvascular plasticity in ageing Ageing Res Rev 2003;2:149-68.

53 De Leeuw F, Barkhof F, Scheltens P. Alzheimer's disease-one clinical syndrome, two radiological expressions: a study on blood pressure. J Neurol Neurosurg Psychiatry 2004:75:1270-4.

54 Schneider J, Wilson R, Cochran E, et al. Relation of cerebral infarctions to dementia and cognitive function in older persons. Neurology 2003; 1:1082-8

55 Langa K, Foster N, Larson E. Mixed dementia. JAMA 2004;292:2901-8.

56 Fratiglioni L, Launer L, Anderson K, for the Neurologic Diseases in the Elderly Research Group, et al. Incidence of dementia and major subtypes in Europe: a collaborative study of population-based cohorts. Neurology 2000;54:S10-15.

57 Gold G. Reevaluating the role of vascular changes in the differential diagnosis of Alzheimer's disease and vascular dementia. Eur Neurol 1998;40:121-9.

58 Torre J. Alzheimer disease as a vascular disorder nosological evidence. Stroke 2002;33:1152-62.

59 Blauw G, Bollen E, Buchem $M$, et al. Dementia at old age: a clinical endpoint of atherosclerotic disease. Eur Heart J 2001; (suppl 3):N16-19.

60 Barker W, Luis C, Kashuba A, et al. Relative frequencies of Alzheimer disease, Lewy body, vascular and frontotemporal dementia, and hippocampal sclerosis in the State of Florida Brain Bank. Alzheimer Dis Assoc Disord 2002;16:203-12

61 Sparks D, Scheff S, Liu H, et al. Increased incidence of neurofibrillary tangles (NFT) in non-demented individuals with hypertension. J Neurol Sci 1995;131:162-9

62 Jellinger K. Alzheimer disease and cerebrovascular pathology: an update. J Neural Trans 2002;109:813-36.

63 Breteler M. Vascular involvement in cognitive decline and dementia. Ann New York Acad Sci 2000;903:457-65

64 Ellis R, Olichney J, Thal L, et al. Cerebral amyloid angiopathy in the brains of patients with Alzheimer's disease: the CERAD experience, part XV. Neurology 1996;46:1592-6.

65 Jellinger K, Mitter-Ferstl E. The impact of cerebrovascular lesions in Alzheimer's disease. J Neurol 2003;250:1050-5.

66 Lee J, Olichney J, Hansen L, et al. Small concomitant vascular lesions do not influence rates of cognitive decline in patients with Alzheimer's disease. Arch Neurol 2000;57:1474-9.

67 Stewart R. Cardiovascular factors in Alzheimer's disease. J Neurol Neurosurg Psychiatry 1998:65:143-7.

68 Rigaud S, Seux M, Staessen J, et al. Cerebral complications of hypertension. $J$ Hum Hypertens 2000;14:605-16.

69 Schmidt R, Schmidt H, Fazekas F. Vascular risk factors in dementia. J Neurol 2000;247:81-7.

70 Xuereb J, Brayne C, Dufouil C, et al. Neuropathological findings in the very old. Ann New York Acad Sci 2000;903:491-6. 
71 Wen W, Sachdev P. The topography of white matter hyperintensities on brain MRI in healthy 60- to 64-year-old individuals. Neurolmage 2003;22:144-54.

72 Silver M, Newell K, Brady C, et al. Distinguishing between neurodegenerative disease and disease-free ageing: correlating neuropsychological evaluations and neuropathological studies in centenarians. Psychosom Med 2002;64:493-501.

73 Perls T. Centenarians who avoid dementia. Trends Neurosci 2004; $27: 633-6$

74 Hof $\mathbf{P}$, Morrison J. The ageing brain: morphomolecular senescence of cortical circuits. Trends Neurosci 2004;27:607-13.

75 Arneiz E, Almkvist O, Ivnik R, et al. Mild cognitive impairment: a crossnational comparison. J Neurol Neurosurg Psychiatry 2003;75:1275-80.

76 Grundman M, Petersen R, Ferris S, for the Alzheimer's disease co-operative study, et al. Mild cognitive impairment can be distinguished from Alzheimer's disease and normal ageing for clinical trials. Arch Neurol 2004;61:59-66.

77 Pfefferbaum A, Sullivan E, Carmelli D. Morphological changes in brain structures are differentially affected by time-linked environmental influences despite strong genetic stability. Neurobiol Ageing 2004;25:175-83.

78 Teter B, Finch C. Caliban's heritance and the genetics of neuronal ageing. Trends Neurosci 2004;27:627-3.

79 Mattson M, Chan S, Duan W. Modification of brain ageing and neurodegenerative disorders by genes, diet and behaviour. Physiol Rev 2002:82:637-72.

80 Shepherd J, Blauw G, Murphy M, on behalf of the PROSPER study group, et al. Pravastatin in elderly individuals at risk of vascular disease (PROSPER): a randomised controlled trial. Lancet 2002:1-8,

81 Budge $M$, Johnston $C$, Hogervorst $E$, et al. Plasma total homocysteine and cognitive performance in a volunteer elderly population. Ann New York Acad Sci 2000;903:407-10.

82 Joosten E. Homocysteine, vascular dementia and Alzheimer's disease. Clinical Chemical Laboratory Medicine 2001;39:717-20.

83 Sastre A, Grimley Evan J. Effect of the treatment of type II diabetes mellitus on the development of cognitive impairment and dementia. Cochrane Library. Issue 2. Oxford: Update Software, 2003.

84 Fontbonne A, Berr C, Ducimetiere $P$, et al. Changes in cognitive abilities over a 4 year period are unfavourably affected in elderly diabetic subjects: results of the epidemiology of vascular ageing study. Diabetes Care 2001;24:366-70.

85 Bruce D, Casey G, Grange V, et al. Cognitive impairment, physical disability and depressive symptoms in older diabetic patients: the Freemantle cognition in diabetes study. Diabetes Res Clin Pract 2003:61:59-67.

86 Prins N, Den Heijer T, Hofman A, et al. Homocsteine and cognitive function in the elderly. Neurology 2002;59:1375-380.

87 Kado D, Karlamangla $A$, Huang $M$, et al. Homocysteine versus the vitamins folate, B6, and B12 as predictors of cognitive function and decline in older high-functioning adults: MacArthur studies of successful ageing. Am J Med 2005; 118:161-7.
88 Otsuka M Yamaguchi K, Ueki A. Similarities and differences between Alzheimer's disease and vascular dementia from the viewpoint of nutrition. Ann New York Acad Sci 2002;977:155-61.

89 Mattson $M$. Will calorific restriction and folate protect against $A D$ and PD? Neurology 2003;60:690-5.

90 Barja G. Free radicals and ageing. Trends Neurosci 2004;27:595-600.

91 Bodles A, Barger S. Cytokines and the ageing brain-what we don't know might help us. Trends Neurosci 2004;27:621-6.

92 He K, Song Y, Daviglus $M$, et al. Fish consumption and incidence of stroke. A meta-analysis of cohort studies. Stroke 2004;35:1538-42.

93 Zandi P, Anthony J, Khachaturian A, for the Cache county study group, et al. Reduced risk of Alzheimer disease in users of antioxidant vitamin supplements. Arch Neurol 2004:61:82-8.

94 McDaniel M, Maier S, Einstein G. 'Brain-specific' nutrients: a memory cure? Nutrition 2003; 19:957-5.

95 Heijer T, Vermeer S, Dijk E, et al. Alcohol intake in relation to brain magnetic resonance imageing findings in older persons without dementia. Am J Clin Nutr 2004;80:992-7.

96 Mukamal K, Kuller L, Fitzpatrick A, et al. Prospective study of alcohol consumption and risk of dementia in older adults. JAMA 2003;289:1405-13.

97 Ruitenberg A, Swieten J, Witteman J, et al. Alcohol consumption and risk of dementia: the Rotterdam study. Lancet 2002;359:281-6.

98 Larrieu S, Letenneur L, Helmer C, et al. Nutritional factors and risk of incident dementia in the PAQUID longitudinal cohort. J Nutr Health Ageing 2004:8:150-4.

99 Kramer A, Hahn S, Cohen N, et al. Ageing, fitness and neurocognitive function. Nature 1999;400:418-19.

100 Colcombe S, Erickson K, Raz N, et al. Aerobic fitness reduces brain tissue loss $n$ ageing humans. J Gerontol 2003;58A:176-80.

101 Piguet O, Grayson D, Broe A, et al. Normal ageing and executive functions in the 'old-old' community dwellers poor performance is not an inevitable outcome. Int Psychogeriatr 2002;14:139-59.

102 Shenkin S, Bastin M, MacGillivray T, et al. Childhood and current cognitive function in healthy 80 -year-olds: a DT-MRI study. NeuroReport 2003; 14:345-9.

103 Staff R, Murray A, Deary I, et al. What provides cerebral reserve? Brain 2004;127:1191-9.

104 Green S, Kaye J, Ball M. The Oregon brain ageing study: neuropathology accompanying healthy ageing in the oldest old. Neurology 2000:54:105-21.

105 Rabbitt P, Chetwynd A, Mclnnes L. Do clever brains age more slowly? Further exploration of a nun result. Br J Psychol 2003;94:63-71.

106 Hertzog C. Does longitudinal evidence confirm theories of cognitive ageing derived from cross-sectional data? In: Dixon R, Bäckman L, Nilsson L, eds. New frontiers in cognitive ageing. Oxford: Oxford University Press, 2004:41-64. 